\title{
2013 Conference Theme Statement
}

\section{Power and Persuasion}

PROGRAM CO-CHAIRS: CATHERINE BOONE, THE UNIVERSITY OF TEXAS, AUSTIN AND

ARCHON FUNG, HARVARD UNIVERSITY

\section{APSA Annual Meeting, Chicago, Illinois August 29-September 1, 2013}

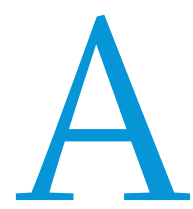

$s$ the world becomes more interdependent and its governance more complex, both within and between nation-states, the two biggest resources for human cooperation - persuasion and legitimate coercive power - become harder to generate across cultural and linguistic lines and sovereign boundaries. Yet the future will require more of these resources. To help societies meet the needs for political interactions of increasing complexity and scale, political scientists need to understand better the uses and abuses of both persuasion and power in varying contexts and scales. This year's program theme encourages scholars to consider the politics of persuasion and power, along with their many intersections.

Politics can be modeled as a series of battles, decided by the preponderance of coercive power. It can also be modeled as the result of common deliberations, decided primarily by persuasion. In practice, different political institutions, including elections, political negotiations, administrative and judicial decisions, and international treaties, combine the elements of force, threats of sanction, incentives, manipulation, and genuine persuasion in different amounts and with different interactions. Actors working outside of institutions also deploy mixes of power and persuasion in efforts to shape the world around them.

Different traditions in the history of our profession have stressed different features in this mix. Empirically oriented political scientists have tended to focus on battles for power through electoral or other means. Although empirical analysts of elections, political parties, social movements, popular opinion, presidential power, international relations, and other areas also study processes of persuasion, in general the study of persuasion and the formulation of the common good has tended to fall more into the bailiwick of political theorists, ethicists, and scholars who study the construction of norms. The dynamics of power and persuasion determine whether processes of decision-making are inclusive, and whether outcomes are fair or effective. Political actors use power and persuasion to formulate a shared understanding of a common goal and to overcome obstacles to collective action.

Today the question of how "persuasive politics" can work at the grassroots level to shape politics from the bottom up - by galvanizing constituencies and collective action, setting standards for the legitimate use of public authority, speaking truth to power, or making claims on the state - demands our renewed attention. At the commanding heights of national and international political institutions, persuasion is also essential. By attempting to define the possible and the desirable in these arenas, and by shaping expectations, actors use varying degrees of coercive power and varying forms of persuasion to try to reshape political agendas, political arenas, and basic conceptions of the common good.

The 2013 theme directs attention to the interplay of structure and agency in politics, and to the spaces of contingency and fluidity that increasingly demand our attention. We hope to entice analysts who have traditionally approached their subject from the perspective of either power or persuasion to play with the possibilities in the other perspective. We also encourage boundary-crossing in other respects, including collaboration between empirical and normative scholars. We hope that these activities will emerge as we invite panels and papers, from a variety of theoretical and empirical perspectives, on the theme of how persuasion and power are combined and contested in different political settings, and with what results. 